\title{
Numerical Analysis of 3D Model of the SSAW Separator System
}

\author{
Bahareh Haddadi \\ Department Of Engineering, \\ Central Tehran Branch, \\ Islamic Azad University, Tehran, Iran
}

\author{
Morteza Fathipour \\ School Of Electrical and \\ Computer Engineering, \\ Tehran University, Tehran, Iran
}

\begin{abstract}
In this paper we investigate a microfluidic device designed for separation of particles having different densities. Separating mechanism employs Standing Surface Acoustic Waves (SSAWs). Simulation studies have shown that Polyethylene microspheres with diameter of $10 \mu \mathrm{m}$, having a density of $1200 \mathrm{~kg} / \mathrm{m} 3$, can easily be detected from the same sized Melamine microspheres having a density equal to 1710 $\mathrm{kg} / \mathrm{m} 3$.
\end{abstract}

\section{Keywords}

SSAW, IDT, density-based.

\section{INTRODUCTION}

Standing surface acoustic waves are among important techniques used for separation of micron sized particles. In the recent years, we have witnessed high degree of interest in employing ultrasonic waves in microfluidic systems due to their lower power consumption, flexible design, and easy integration with microfluidic other devices because of their lower power consumption, flexible design, and easy integration with microfluidic devices. Such devices have been employed to manipulate micron sized particles in the field of cancer cell detection, drug screening, and tissue engineering [1-4]. Nevertheless other methods capable of particle separation in microfluidic systems have also been introduced, including centrifugal [5-7], magnetic [8,9] and hydrodynamic [10] methods. Microfluidic has enabled a number of new approaches for the manipulation of cells and particles. Among the existing active cell separation methods, acoustophoresis, arising from the interaction between acoustic waves and suspended particles, has emerged as a promising technique for non-contact manipulation. Acoustic waves have the potential to make an acoustical force on particles based on their physical properties. Among acoustic waves, standing surface acoustic waves (SSAWs), are of proper form for manipulating particles. Since dissimilar cells differ in their physical properties such as size and density, they react differently to the acoustic waves. Among other passive and active techniques, acoustophoresis is a suitable technique to separate particles and cells based on density differences. Generally acoustic-based microfluidic devices employ a bulk acoustic transducer to generate standing wave, along with materials which have excellent acoustic reflection coefficient [11-16]. Density-based separation techniques are critical for many chemical and biological applications, such as white blood cell classification [22], stem cell isolation [23], foetal cell collection from maternal blood [24], and specific bacterium sorting [25]. There have been some density-based separation studies using passive techniques [26-28]. Standing surface acoustic wave (SAW), generated using a pair of Inter Digitated Transducers (IDTs) . Surface Acoustic Wave is a mechanical acoustic wave that propagates along the surface of a solid material. These waves are generated by applying electrical signals to IDTs. The IDTs, which are placed on piezoelectric substrate, convert the electrical signals into mechanical waves inside the piezoelectric substrate [17]. The wavelength of the surface acoustic waves generated by the IDTs matches the period of the pairs of electrodes in IDT. The SAW-based manipulation has been successfully applied to separate synthetic particles with dissimilar sizes $[18,19]$, and platelets from a blood sample [20]. In [20] a 2D microfluidic system capable of separating particles according to their density differences was designed and simulated. Yet, 2D models have restrictions in defining boundary conditions and do not provide a viable picture of practical situations. On the other hand, numerical simulations of acoustophoretic motion of microparticles can provide efficient prediction of experiments and provide effective optimization on the design of acoustofluidic devices to enhance or improve experiments. While 3D simulations are more realistic than the 2D simulations, existing models for acoustic based separation devices employ 2D simplifications that consider only a crosssectional area of the fluid chamber. This is due to the high computational demand of 3D simulations. In these models, the acoustic field in the fluid layer is generally assumed to have a periodic distribution of constant amplitude as obtained from a uniform distribution of boundary vibration. However, in real acoustofluidic devices, the acoustic field generated from the transducer does not always have a perfectly uniform distribution along the channel axis due to lateral modes, structural modes, transducer inhomogeneity and acoustic absorption at the 2 ends of the channel. Therefore, results obtained from simplified many 2D models cannot fully represent real acoustofluidic devices and 3D models are necessary to provide better understanding and prediction of experiments. Most recently a study demonstrated successfully sheath less size-based particle separation using SSAW in a two-stage microfluidic channel.

In this paper, we consider separation of two particles having the same size but with different densities using a 3D microfluidic system. This study demonstrates how 3D models can improve the understanding of the particle behaviours inside the microchannel. In section 2 we discuss device parameters used in the simulation study. Section 3.describes the separation system

\section{DEVICE PARAMETERS}

The microfluidic device is composed of two parts, a SAW transducer and a PDMS channel. We assume that the SAW transducer is built of aluminium and is deposited on a $128^{\circ}$ rotated Y-cut X-propagating $\mathrm{LiNbO} 3$ substrate. SAWs are propagated in the substrate in a depth equal to two to three times of wavelength, Thus the thickness of LiNbO3 selected $1600 \mu \mathrm{m}$. The resonant frequency of the SAW transducer is determined by the electrode size and the space between two 
adjacent electrodes. The width of electrode and the spacing between them are both $100 \mu \mathrm{m}$. Therefore, the SAW wavelength is $\lambda=400 \mu \mathrm{m}$, implying a resonant frequency around $9.9 \mathrm{MHz}$, given the fact that the speed of sound in LiNbO3 is approximately $3990 \mathrm{~m} / \mathrm{s}$. The PDMS channel width is $200 \mu \mathrm{m}$ which is half of a wavelength. The model parameters are summarised in Table. 1 and includes particle properties used in particle trajectory simulations.

Table1. Model parameters in simulation

\begin{tabular}{|c|c|c|c|}
\hline $\begin{array}{c}\text { Width of } \\
\text { microchannel } \\
\text { in first stage }\end{array}$ & $\begin{array}{l}200 \\
\mu m\end{array}$ & $\begin{array}{c}\text { Width of } \\
\text { microchannel } \\
\text { in first stage }\end{array}$ & $\begin{array}{l}400 \\
\mu m\end{array}$ \\
\hline $\begin{array}{c}\text { Length of } \\
\text { microchannel }\end{array}$ & $\begin{array}{l}1000 \\
\mu m\end{array}$ & $\begin{array}{c}\text { Width of } \\
\text { IDT }\end{array}$ & $\begin{array}{l}100 \\
\mu m\end{array}$ \\
\hline $\begin{array}{l}\text { Density of } \\
\text { particle } 1\end{array}$ & $\begin{array}{c}1200 \\
\mathrm{~kg} / \mathrm{m}^{3}\end{array}$ & $\begin{array}{c}\text { Length of } \\
\text { IDT }\end{array}$ & $\begin{array}{l}800 \\
\mu m\end{array}$ \\
\hline $\begin{array}{l}\text { Density of } \\
\text { particle } 2\end{array}$ & $\begin{array}{c}1710 \\
\mathrm{~kg} / \mathrm{m}^{3}\end{array}$ & $\begin{array}{l}\text { Number of } \\
\text { IDT fingers }\end{array}$ & $\begin{array}{c}10 \\
\text { pairs }\end{array}$ \\
\hline $\begin{array}{c}\text { Speed of } \\
\text { sound in } \\
\text { water }\end{array}$ & $\begin{array}{l}1481 \\
\mathrm{~m} / \mathrm{s}\end{array}$ & $\begin{array}{l}\text { Density of } \\
\text { water }\end{array}$ & $\begin{array}{c}998 \\
\mathrm{~kg} / \mathrm{m}^{3}\end{array}$ \\
\hline $\begin{array}{l}\text { Speed of } \\
\text { sound in } \\
\text { particle1 }\end{array}$ & $\begin{array}{l}2350 \\
\mathrm{~ms}^{-1}\end{array}$ & Mesh size & fine \\
\hline $\begin{array}{l}\text { Speed of } \\
\text { sound in } \\
\text { particle } 2\end{array}$ & $\begin{array}{l}1292 \\
\mathrm{~ms}^{-1}\end{array}$ & $\begin{array}{c}\text { Excitation } \\
\text { voltage }\end{array}$ & $10 \mathrm{~V}_{\mathrm{p}-\mathrm{p}}$ \\
\hline
\end{tabular}

\section{SEPARATION SYSTEM}

\subsection{System mechanism}

Figure (1) illustrates the basic principle governing separation of the particle when using standing SAW field with two stages. A microchannel made of PDMS is placed between two IDTs to construct the microfluidic device. Particles are released in a narrow channel filled with water. Separating process takes place in two stages. The SSAW field generated by AC excitation of a pair of IDTs patterned on the piezoelectric material, LiNbO3. Interdigitated Transducers (IDTs) have long been used to generate surface and bulk acoustic waves for a variety of applications [29]. Their popularity is due in part to versatility, ease and low cost of manufacture, and suitability for mass production. IDTs find application to a wide variety of device classes where a requirement exists for the generation of elastic waves in solids. An IDT structure consists of interdigitated electrodes patterned in metal via photolithography or other means on a piezoelectrically active substrate or layer. Mode selectivity, excitation strength, wave directivity, size and relatively low cost are the most important advantages of IDTs. Excitation strength which is related to the length of IDTs is different in two stages. In the first stage which particles have to be focused on the midline, particle need more time to migrate to the middle part of the microchannel. But in the second stage particles need less time to reach to the target point. So, the length of IDT should change. Governing equations are discussed below.

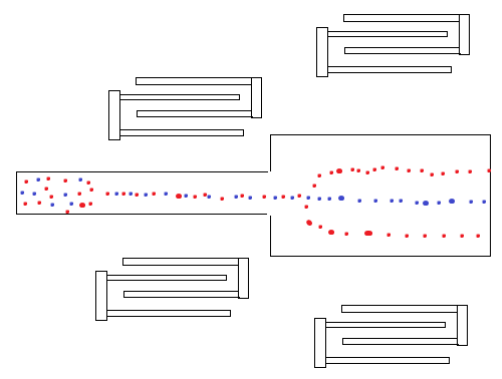

Fig 1: Two stage particle SSAW separator according to density

\subsection{Acoustic Radiation Force}

Acoustic radiation force (ARF) control the motion of the particles within the microchannel filled by fluid medium. Different factors affect the ARF. As mentioned in Eqs.(1)-(3), particle properties such as radius, density and compressibility affect ARF. The direction of acoustic force determined by the sign of contrast factor whether the acoustic radiation force is directed to the pressure node (PN) or antipressure node (APN). Particles with positive contrast factor reach PNs, on the other hand, particles with negative contrast factor go to APNs. Generally, solid particles and cells have positive contrast factor, and are attracted to the PNs. In this device, the channel width is half of an acoustic wavelength. The design of the first IDT stages is such that pressure node is generate right in the middle of the microchannel while in the second stage IDTs are shifted by $100 \mu \mathrm{m}$ to the right. Pressure nodes are formed at two sidewalls. The particles are assumed to have the same size but different densities. During the time interval that particles pass through the first stage, all particles is focused in the midline, while they pass during the second stage, particles with lower density stay in midline and denser particles reach the pressure nodes in the side walls. This is because denser particles experience larger force and reach pressure nodes earlier than the others. The acoustic radiation force acting on a micron-sized particle in an acoustic field is given by the following equations :

$F_{\text {rad }}=-\nabla U_{\text {rad }}$

where $U_{\text {rad }}$ is the radiation potential,

$U_{\text {rad }}=\frac{4 \pi}{3} r^{3}\left[f_{1} \frac{1}{2 \rho_{f} c_{f}{ }^{2}}\left\langle p_{i n}{ }^{2}\right\rangle-f_{2} \frac{3}{4} \rho_{f}\left\langle v_{i n}{ }^{2}\right\rangle\right]$

$f_{1}=1-\frac{\rho_{f} c_{f}{ }^{2}}{\rho_{p} c_{p}{ }^{2}} \quad \& \quad f_{2}=\frac{2\left(\rho_{p}-\rho_{f}\right)}{2 \rho_{p}+\rho_{f}}$

Where $\mathrm{r}$ is the radius of the spherical particle, $\rho_{p}$ is the density of the particle, $\rho_{f}$ is the density of the suspension fluid, $c_{p}$ is the speed of sound inside the particle, and $c_{f}$ is the speed of sound inside the suspension fluid [30]. The Eqs. (1)-(3) show that the acoustic force applied on particles according to their physical properties such as size, density and compressibility. The SSAW separator doesn't need any sheath flow to focus particles in the midline. The exposing time of particles are simulated.

\section{NUMERICAL MODEL}

An AC signal with the amplitude of $10 \mathrm{Vp}$-p was applied to the IDTs to drive the SAW transducer to generate a standing SAW field across the channel. An impedance analysis of the fabricated SAW transducer was conducted to find the practical resonant frequency using piezoelectric module (pzd) in COMSOL software. To apply AC voltage electrical circuit 
(cir) module was used. By coupling "pzd" and "cir" modules in COMSOL multiphysics, it is possible to simulate piezoelectric displacement. Fig 2, reveals that the resonance frequency is around $9.4 \mathrm{MHz}$ which confirms results provided by other researchers .

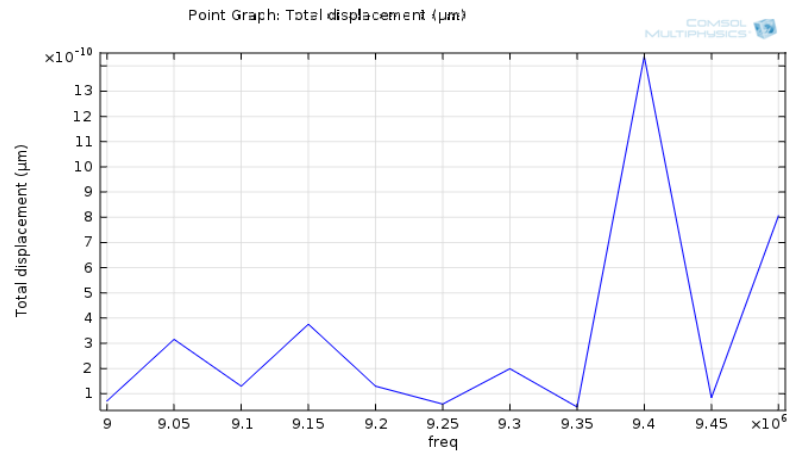

Fig 2: Total displacement of $\mathrm{LiNbO3}$ graph versus frequency

Total displacement of the piezoelectric material at resonance frequency is shown in Fig 3. The red parts have positive voltage and the yellow ones are negative. By applying sinusoidal voltage to the electrodes the substrate will have positive and negative peaks.

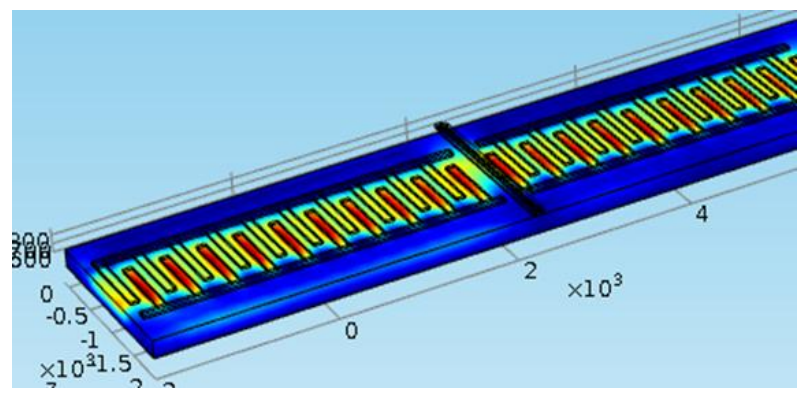

Fig 3: Total displacement of $\mathrm{LiNbO3}$ in 3D

Solid mechanics (solid) module was used to model PDMS and LiNbO3 domains. PDMS and LiNbO3 are both isotropic elastic material. The boundary load condition was applied to the interface between PDMS and $\mathrm{LiNbO3}$, and $\mathrm{LiNbO} 3$ known as acoustic load per unit area (acpr/pam1) in solid mechanics module. Once the two SAWs meet the solid and fluid layers, the harmonic vibration of the piezoelectric substrate partially radiates acoustic waves into the two layers. For the elastic mechanical motion arising from the piezoelectric effect, the surface with interdigitated electrodes, excluding boundaries in contact with the fluid and solid domains, was set to free, referring to no force loads or constraints. Fluid domain was modeled by acoustic pressure module (acpr) in frequency domain and laminar flow in stationary state study. The inlet and outlet boundary condition was applied to the input and output of the microchannel. Because of the interaction between the elastic mechanical motion and acoustic pressure field, a force load was applied on the boundaries in contact with the fluid and solids domains, known as normal acceleration, T.n= -p.n . The left and right walls were considered as plane wave radiation boundary conditions and the remaining walls as hard boundaries. By placing IDTs in two sides of microchannel with the distance of $100 \mu \mathrm{m}$ from the right side of microchannel and $200 \mu \mathrm{m}$ from the left side, Pressure node generates in the middle of the microchannel. Fig 4, shows 3D schematic of microchannel with the pressure node in the midline.

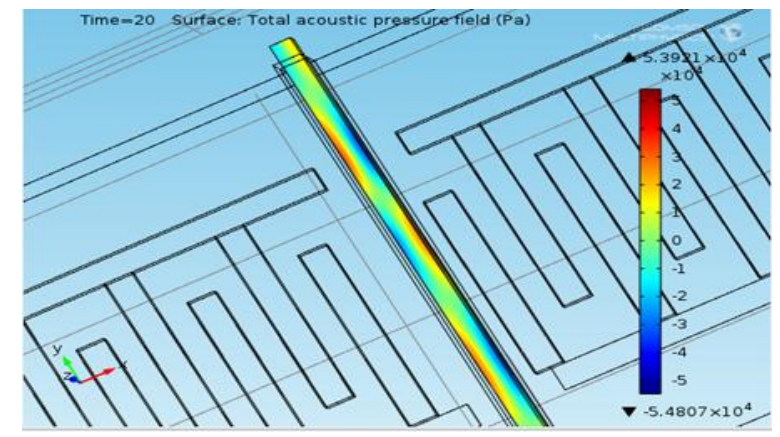

Fig 4: Pressure node in the midline in 3D simulation

Similarly, to generate two pressure nodes in the sidewalls, two IDTs were placed with the distance of $15 \mu \mathrm{m}$ from the right side of microchannel and $100 \mu \mathrm{m}$ from the left. Fig 5, shows $3 \mathrm{D}$ schematic of microchannel with the pressure node in the sidewalls.

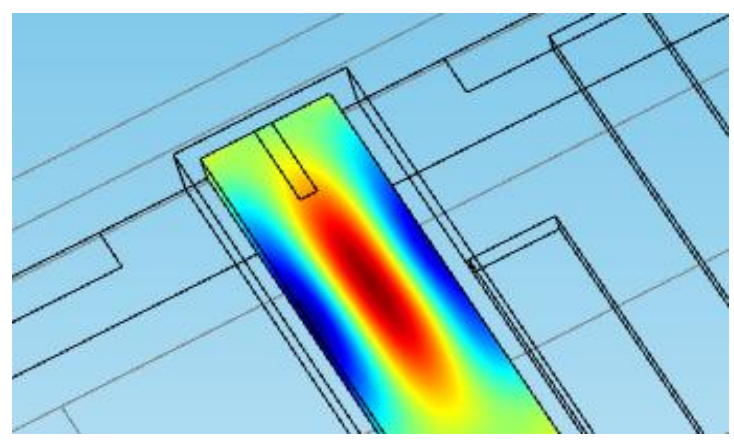

Fig 5: Pressure node in the sidewalls in 3D simulation

\section{SIMULATION RESULTS}

As discussed before, separation has two steps. In first stage, particles focus in midline, then particles with two different densities go to the pressure nodes in sidewalls of the microchannel. The COMSOL 'Particle Tracing for Fluid Flow' module is used to simulate the particle trajectories. Particles released inside the microchannel with the initial velocity of $0.5 \mu \mathrm{m} / \mathrm{s}$. The following Figures $6 \mathrm{a}$ to $6 \mathrm{~d}$ show of particles passing with the density of $1710 \mathrm{~kg} / \mathrm{m} 3$ and 1200 $\mathrm{kg} / \mathrm{m} 3$ at different time steps.

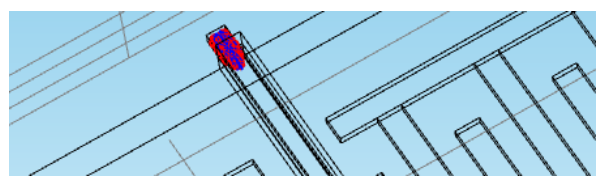

Figure 6a: Particle movement at $\mathrm{t}=0 \mathrm{~s}$

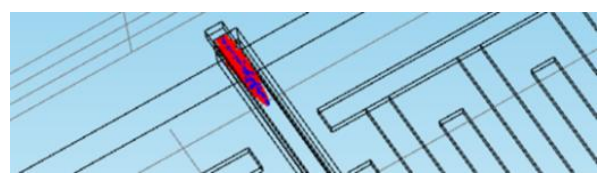

Figure 6b: Particle movement at $\mathrm{t}=4 \mathrm{~s}$

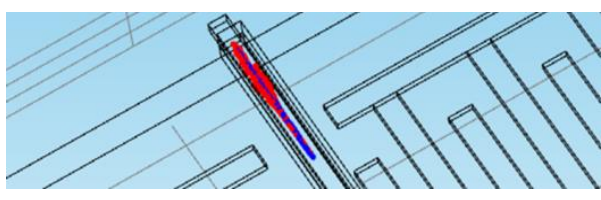

Figure 6c: Particle movement at $t=8 s$ 


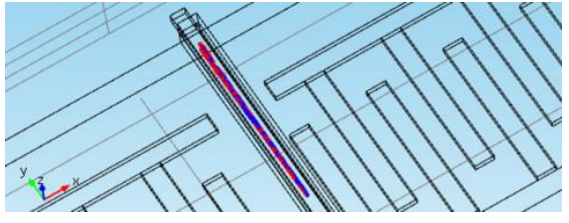

Figure 6d: Particle movement at $\mathrm{t}=\mathbf{1 4 s}$

Particles with the density of $1710 \mathrm{~kg} / \mathrm{m} 3$ showed in red and with the density of $1200 \mathrm{~kg} / \mathrm{m} 3$ are in blue. With the initial velocity of $0.5 \mu \mathrm{m} / \mathrm{s}$ both of particles released. It takes around $14 \mathrm{~s}$ after releasing particles through the inlet to focus in midline. In the second stage particles arrow in 2 lines in the corners. As shown in figures $7 \mathrm{a}$ to $7 \mathrm{~d}$.

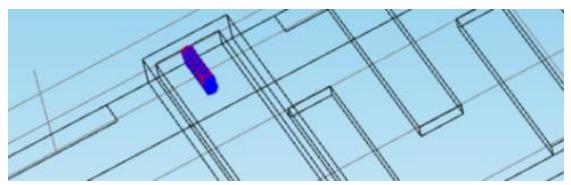

Figure 7a: Particle release in second step at $\mathrm{t}=0 \mathrm{~s}$

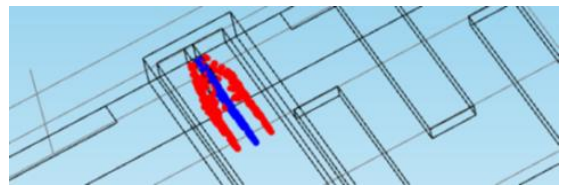

Figure 7b: Particle release in second step at $t=1 \mathrm{~s}$

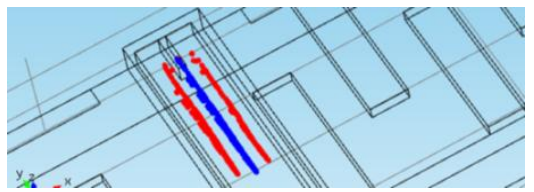

Figure 7c: Particle release in second step at $t=4 s$

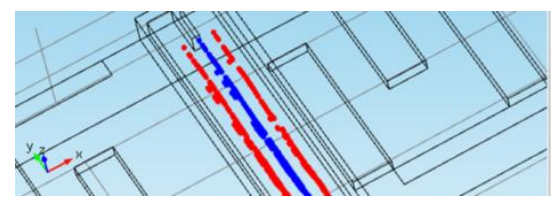

Figure 7d: Particle release in second step at $t=7 \mathrm{~s}$

Figures $8 \mathrm{a}$ to $8 \mathrm{~d}$, show particle distribution at different time steps. As expected, particles with the lower density (blue) do not no experience sufficient force to reach the pressure nodes , remaining on the midline. Conversely, denser particles (shown in red) do experience sufficient force and thus can reach the pressure nodes and thus separation will take place. The time needed for each particle to reach the pressure node is different and has to be estimated. The exposure time and flow rate are two key factors for good separation efficiency. Figures $7 \mathrm{a}$ to $7 \mathrm{~d}$ show the exposure time needed to push particles with the density of $1200 \mathrm{~kg} / \mathrm{m} 3$ to the targeted points:

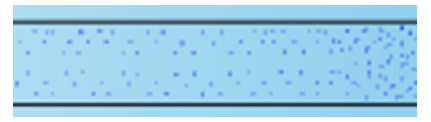

Figure 8a: Particle distribution at $\mathrm{t}=0 \mathrm{~s}$

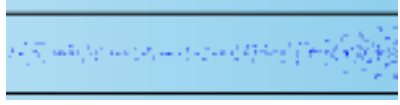

Figure 8b: Particle distribution at $\mathbf{t}=\mathbf{0 . 0 1 \mathrm { s }}$

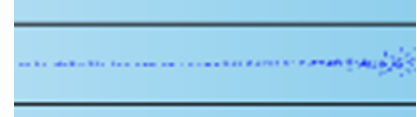

Figure 8c: Particle distribution at $\mathrm{t}=0.02 \mathrm{~s}$

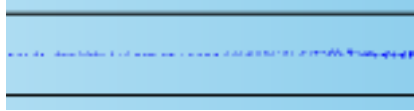

Figure 8d: Particle distribution at $\mathbf{t}=\mathbf{0 . 0 3 s}$

Figures $9 \mathrm{a}$ and $9 \mathrm{~b}$ show the exposing time of the particles with lower density $(1200 \mathrm{~kg} / \mathrm{m} 3)$ comparing to particles:

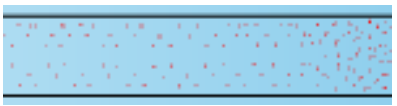

Figure 9a: Particle distribution at $\mathrm{t}=0 \mathrm{~s}$

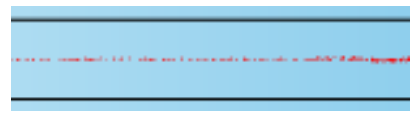

Figure 9b: Particle distribution at $\mathrm{t}=0.01 \mathrm{~s}$

The simulation results show that denser particles (red), reach to pressure nodes faster than denser particles (blue). For the second stage, exposure time of particles having densities equal to 1710 and $1200 \mathrm{~kg} / \mathrm{m} 3$ is depicted in the figures $10 \mathrm{a}$ to $10 \mathrm{~d}$.

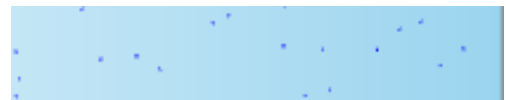

Figure 10a: Particle distribution at $\mathrm{t}=0 \mathrm{~s}$

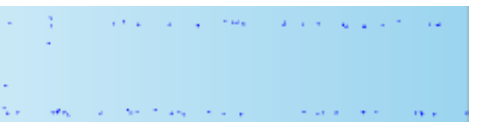

Figure 10b: Particle distribution at $\mathrm{t}=0.07 \mathrm{~s}$

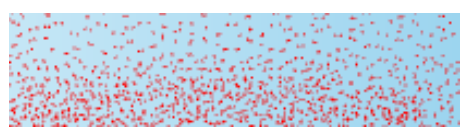

Figure 10c: Particle distribution at $\mathrm{t}=0 \mathrm{~s}$

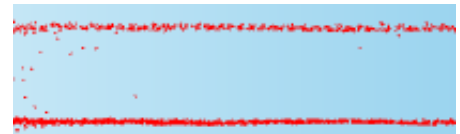

Figure 10d: Particle distribution at $\mathrm{t}=\mathbf{0 . 0 7 \mathrm { s }}$

It can be seen that denser particles reach the pressure node with in $0.01 \mathrm{~s}$ while particles with the lower density need reach the pressure node in $0.07 \mathrm{~s}$. After passing the SSAW active region, the particles remain separated due to laminar flow behavior in the microchannel. So, particles are separated using acoustic force. Figures 12a to 12d, show the acoustic force on a particle at $\mathrm{x}=2301 \mu \mathrm{m}$ and the behavior of particle is discussing around the midline. As the middle part of microchannel is positioned in $\mathrm{x}=2300 \mu \mathrm{m}$ in second stage, it is expected that the particle be pushed to the nearest pressure node in the microchannel. The pressure node is positioned in $\mathrm{x}=2260 \mu \mathrm{m}$ in right hand and $\mathrm{x}=2340 \mu \mathrm{m}$ in the left hand part of the midline. Particles which are far from the pressure nodes experience bigger force. For example particle1 is positioned at $\mathrm{x}=2301 \mu \mathrm{m}$ in the right part of the midline, so it should be 
pushed to the right hand pressure node at $\mathrm{x}=2340 \mu \mathrm{m}$ and should experience a positive acoustic force in $\mathrm{x}$-direction. Also, particles in the left side of the center of the microchannel, reach the left pressure node. These results are shown in figures $11 \mathrm{a}$ and $11 \mathrm{~b}$.

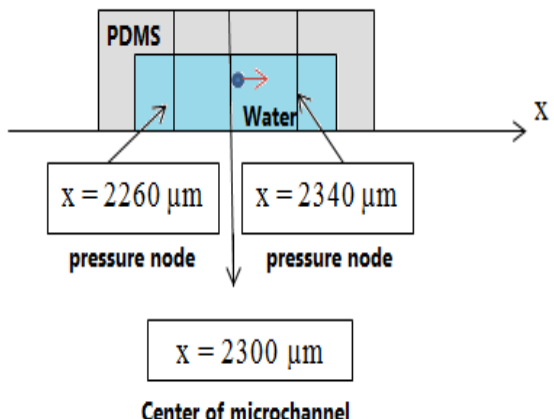

Figure 11a: Particle behavior around the pressure node

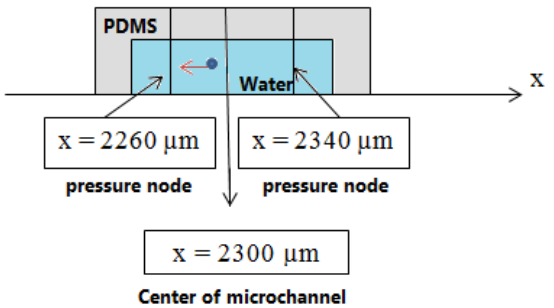

Figure 11b: Particle behavior around the pressure node

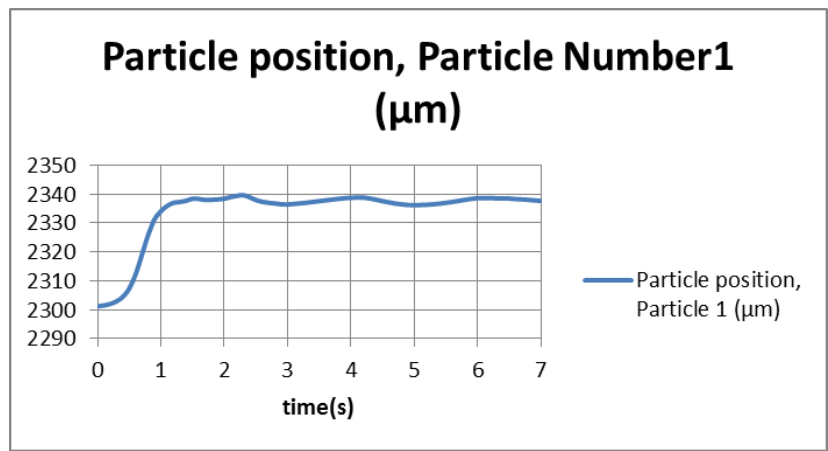

Figure 12a: particle Number1 positions for $7 \mathrm{~s}$

\section{Acoustic Force, $x$ component, Particle Number1 (N)}

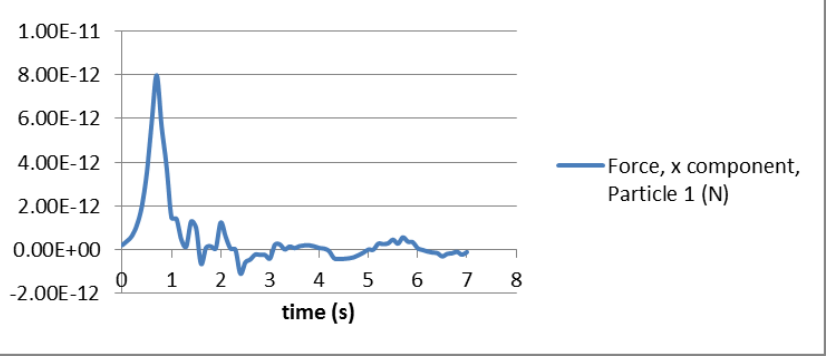

Figure 12b: Acoustic force on the particle Number1

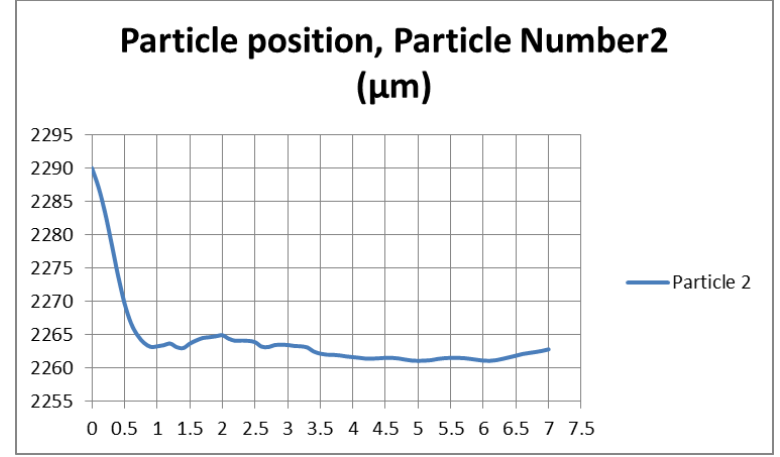

Figure 12c: particle Number2 positions for $7 \mathrm{~s}$

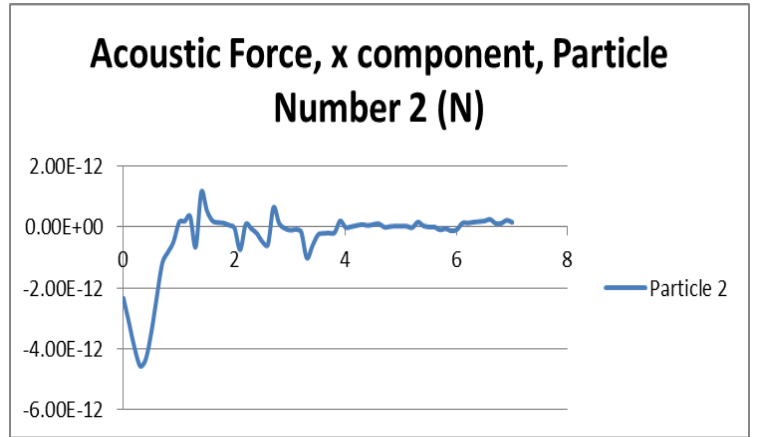

Figure 12d: Acoustic force on the particle Number2

\section{CONCLUSION}

We have discussed simulation results of a particle separator system which uses a SSAWs system. Polyethylene Microspheres and melamine particles both $10 \mu \mathrm{m}$ with the same size in diameter $10 \mu \mathrm{m}$, and density of $1200 \mathrm{~kg} / \mathrm{m} 3$ and $1710 \mathrm{~kg} / \mathrm{m} 3$ were successfully separated. In this study particles having closer densities than those previously reported were studied. The study may be useful for cell detection where separation of particles with similar physical properties is of interest. Cancer cells are of special interest. This technique has the potential to be used in a lab-on-a-chip systems for biomedical application.

\section{REFERENCES}

[1] C. W. Yung, J. Fiering, A. J. Mueller and D. E. Ingber, Micromagnetic-microfluidic blood cleansing device, Lab Chip, 2009, 9, 1171-1177.

[2] O. Lara, X. Tong, M. Zborowski and J. J. Chalmers, Enrichment of rare cancer cells through depletion of normal cells using density and flow-through, immunomagnetic cell separation, Exp. Hematol.,2004, 32, 891-904.

[3] N. Ye, J. Qin, W. Shi, X. Liu and B. Lin, Cell-based high content screening using an integrated microfluidic device, Lab Chip, 2007, 7, 1696-1704.

[4] P. O. Krutzik, J. M. Crane, M. R. Clutter and G. P. Nolan, Flow Cytometry in Drug Discovery and Development, Nat.Chem. Biol., 2008, 4, 132-142.

[5] J. Seo, M. H. Lean and A. Kole, Membrane-free microfiltration by asymmetric inertial migration, Appl. Phys. Lett., 2007, 91, 033901-0339013.

[6] N. Pamme, Continuous flow separations in microfluidic devices, Lab Chip, 2007, 7, 1644-1659.

[7] C. Blattert, R. Jurischka, A. Schoth, P. Kerth and W. 
Menz, Fabrication and testing ofnovel blood separation devices based on microchannel bend structures, Proc.SPIE-Int. Soc. Opt. Eng., 2004, 5345, 17-25.

[8] B. Qu, Z. Wu, F. Fang, Z. Bai, D. Yang and S. Xu, A glass microfluidic chip for continuous blood cell sorting by a magnetic gradient without labelling, Anal Bioanal.Chem., 2008, 392, 1317-1324.

[9] K. McCloskey, J. Chalmers and M. Zborowski, Magnetic cell separation: characterization of magnetophoretic mobility, Anal. Chem., 2003,75, 6868-6874.

[10] M. Yamada, M. Nakashima and M. Seki, Pinched Flow Fractionation: Continuous Size Separation of Particles Utilizing a Laminar Flow Profile in a Pinched Microchannel, Anal. Chem., 2004, 76,5465-5471.

[11] Martin, S. P., Townsend, R. J., Kuznetsova, L. A., Borthwick, K. A. J., Hill, M., McDonnell, M. B., and Coakley, W. T., Spore and micro-particle capture on an immunosensor surface in an ultrasound standing wave system, Biosensors and Bioelectronics, 21(5), 758-767 (2005).

[12] Petersson, F., Nilsson, A., Holm, C., Jonsson, H., and Laurell, T., Continuous separation of lipid particles from erythrocytes by means of laminar flow and acoustic standing wave forces, 'Lab on a Chip, 5(1), 20-22 (2005).

[13] Jung, B., Fisher, K., Ness, K. D., Rose, K. A., and Mariella, R. P., Acoustic Particle Filter with Adjustable Effective Pore Size for Automated Sample Preparation, Analytical Chemistry, 80(22), 8447-8452 (2008).

[14] Koklu, M., Sabuncu, A. C., and Beskok, A., Acoustophoresis in shallow microchannels, Journal of Colloid and Interface Science, 351(2), 407-414 (2010).

[15] Cushing, K. W., Piyasena, M. E., Carroll, N. J., Maestas, G. C., López, B. A., Edwards, B. S., Graves, S. W., and López, G. P., Elastomeric Negative Acoustic Contrast Particles for Affinity Capture Assays, Analytical Chemistry, 85(4), 2208-2215 (2013).

[16] Xia, Y. N., and Whitesides, G. M., Soft lithography,Annual Review of Materials Science, 28, 153-184 (1998).

[17] Ramli, N.A. , Nordin, A.N. , Design and modeling of MEMS SAW resonator on Lithium Niobate, 2011 4th International Conference on Mechatronics (ICOM), 1719 May 2011, Kuala Lumpur, Malaysia.

[18] Shi, J. J., Huang, H., Stratton, Z., Huang, Y. P., and Huang, T. J., Continuous particle separation in a microfluidic channel via standing surface acoustic waves (SSAW), Lab on a Chip, 9(23), 3354-3359 (2009).

[19] Nam, J., Lee, Y., and Shin, S., Size-dependent microparticles separation through standing surface acoustic waves, Microfluidics and Nanofluidics, 11(3), 317-326 (2011).

[20] Nam, J., Lim, H., Kim, D., and Shin, S., Separation of platelets from whole blood using standing surface acoustic waves in a microchannel, Lab on a Chip, 11(19), 3361-3364 (2011).

[21] Yosioka, K., and Kawasima, Y., Acoustic radiation pressure on a compressible sphere, Acustica, 5, 167-173 (1955).

[22] D. English, B.R. Andersen, Single-step separation of red blood-cells, granulocytes and mononuclear leukocytes on discontinuous density gradients of Ficoll-Hypaque, Journal of Immunological Methods 5 (1974) 249-252.

[23] A. Rambaldi, G. Borleri, G. Dotti, P. Bellavita, R. Amaru, A. Biondi, T. Barbui, Innovative two-step negative selection of granulocyte colony-stimulating factor-mobilized circulating progenitor cells: adequacy for autologous and allogeneic transplantation, Blood 91 (1998) 2189-2196.

[24] O. Samura, A. Sekizawa, D.K. Zhen, V.M. Falco, D.W. Bianchi, Comparison of fetal cell recovery from maternal blood using a high density gradient for the initial separation step: 1.090 versus $1.119 \mathrm{~g} / \mathrm{ml}$, Prenatal Diagnosis 20 (2000) 281-286.

[25] T. Chesnot, J. Schwartzbrod, Quantitative and qualitative comparison of density-based purification methods for detection of Cryptosporidium oocysts in turbid environmental matrices, Journal of Microbiological Methods 58 (2004) 375-386.

[26] T. Morijiri, S. Sunahiro, M. Senaha, M. Yamada, M. Seki, Sedimentation pinchedflowfractionation for sizeand density-based particle sorting in microchannels, Microfluidics and Nanofluidics 11 (2011) 105-110.

[27] C.H. Hsu, D. Di Carlo, C.C. Chen, D. Irimia, M. Toner Microvortex for focusing, guiding and sorting of particles, Lab on a Chip 8 (2008) 2128-2134.

[28] O. Ae Gyoung, L. Dong Woo, C. Young-Ho, A continuous cell separator based on buoyant force in dissimilar density fluid flows, in: 2010 IEEE 23rd International Conference on Micro Electro Mechanical Systems (MEMS), 2010, pp.1023-1026.

[29] A.A. Oliner et al., Acoustic Surface Waves. SpringerVerlag, Berlin (1978).

[30] M. Settnes and H. Bruus (2012) "Forces acting on a small particle in an acoustical field in a viscous fluid. 